\title{
Correction to: Imaging Intensity and Survival Outcomes in High- Risk Resected Melanoma Treated by Systemic Therapy at Recurrence
}

Andrea Marie Ibrahim, MSc ${ }^{1}$, Melanie Le May, MD, MSc $^{2}$, Dominick Bossé, MD, MSc, MPH, FRCPC Horia Marginean, MD, MS ${ }^{1}$, Xinni Song, MD, FRCPC ${ }^{3}$, Carolyn Nessim, MD, MSc, FRCSC, FACS ${ }^{4}$, and Michael Ong, MD, FRCPC ${ }^{3}$

${ }^{1}$ Cancer Therapeutics Program, Ottawa Hospital Research Institute, Ottawa, ON, Canada; ${ }^{2}$ Division of Internal Medicine, University of Ottawa, The Ottawa Hospital, Ottawa, ON, Canada; ${ }^{3}$ Division of Medical Oncology, University of Ottawa, The Ottawa Hospital, Ottawa, ON, Canada; ${ }^{4}$ Division of General Surgery, University of Ottawa, The Ottawa Hospital, Ottawa, ON, Canada

CORRECTION TO: ANN SURG ONCOL

HTTPS://DOI.ORG/10.1245/S10434-020-08407-8

In the original article, the survival curves are missing in

Fig. 1c and d. Following is the corrected Fig. 1.

The original article can be found online at https://doi.org/10.1245/ s10434-020-08407-8.

(C) Society of Surgical Oncology 2020

Published Online: 22 May 2020

M. Ong, MD, FRCPC

e-mail:mong@toh.ca 
a

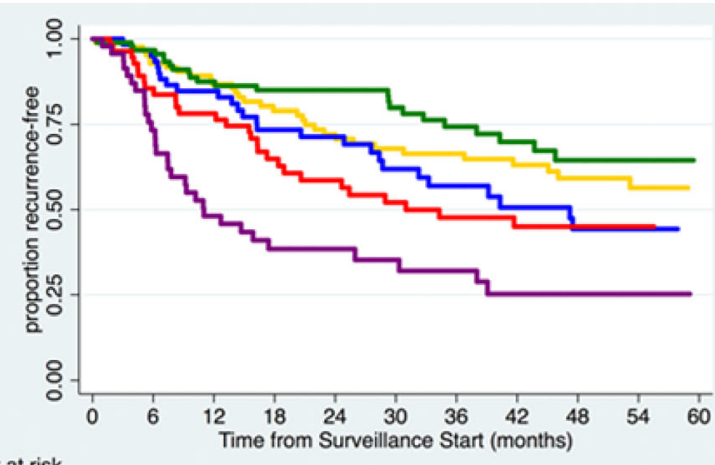

Number at risk

$\begin{array}{llllllllllll}\text { Stage IIC } & 61 & 56 & 46 & 38 & 32 & 25 & 22 & 16 & 14 & 11 & 8\end{array}$

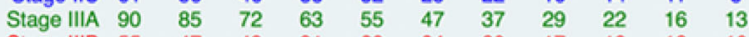

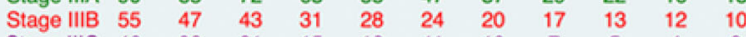

c

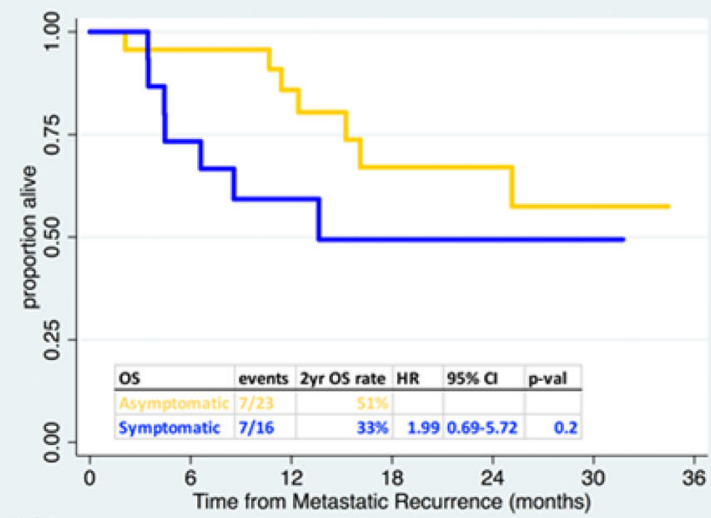

Number at risk

Symptomatic 16 b

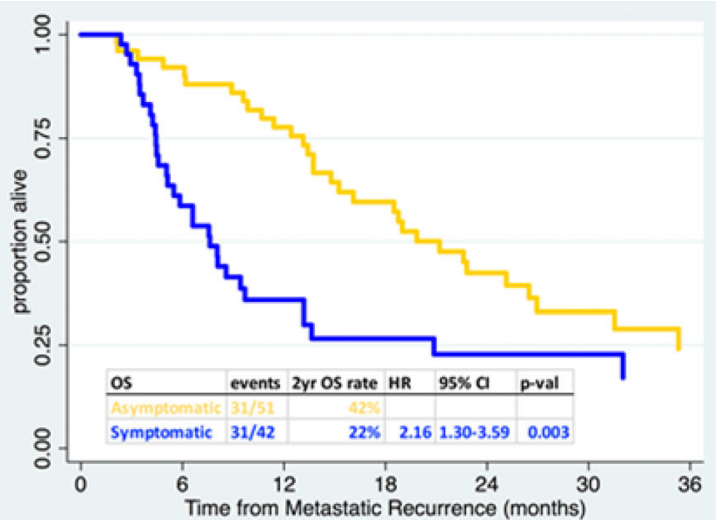

Number at risk

Symptomatic 42

12 d

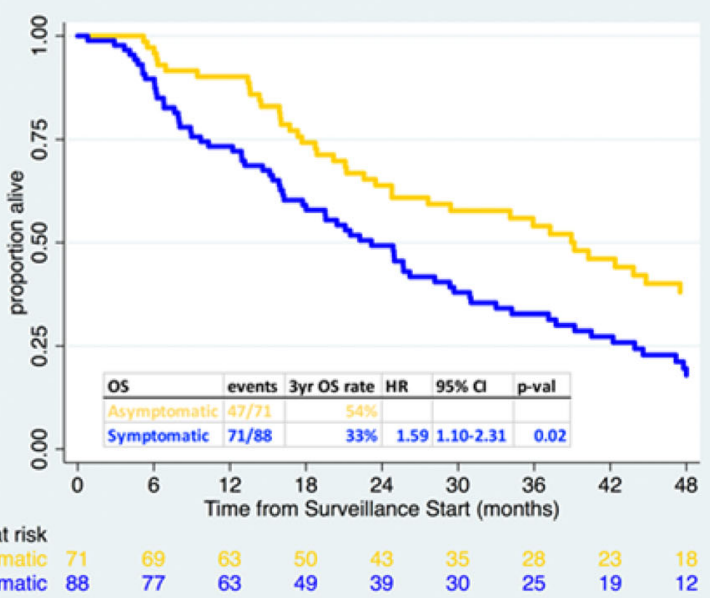

months (SR); HR 1.99, 95\% CI 0.69-5.72; $p=0.2]$. d OS from the start of surveillance stratified by symptom status at recurrence [median survival time 39.2 months (ASDR) vs. 23.2 months (SR); HR $1.59,95 \%$ CI 1.10-2.31; $p=0.02]$. OS overall survival, $H R$ hazard ratio, $C I$ confidence interval, AJCC American Joint Committee on Cancer, $A S D R$ asymptomatic surveillance-detected recurrence, $S R$ symptomatic recurrence, $P D 1$ programmed death receptor-1

Publisher's Note Springer Nature remains neutral with regard to jurisdictional claims in published maps and institutional affiliations. 